\title{
Identification for the Optimal Working Parameters of Ti-6Al-4V-0.1Ru Alloy in a Wide Deformation Condition Range by Processing Maps Based on DMM
}

\author{
Yu-feng Xia ${ }^{a}$, Shuai Long ${ }^{a}$, Yu-ting Zhou ${ }^{a}$, Jia Zhao ${ }^{a}$, Tian-yu Wang ${ }^{a}$, Jie Zhou ${ }^{a}$ \\ a School of Material Science and Engineering, Chongqing University, Chongqing 400044, China
}

Received: June 14, 2016; Revised: September 11, 2016; Accepted: October 20, 2016

\begin{abstract}
The hot deformation behaviours of Ti-6Al-4V-0.1Ru alloy were investigated by isothermal hot compression tests in the temperature range of $1023-1423 \mathrm{~K}$ and strain rate range of $0.01-10 \mathrm{~s}^{-1}$. The $\beta$ transus was determined to be $1198 \mathrm{~K}$ by continuous heating method. The values of deformation activation energy $Q$ at the strain of 0.3 were calculated to be $630.01 \mathrm{~kJ} / \mathrm{mol}$ in dual-phase field and $331.75 \mathrm{~kJ} / \mathrm{mol}$ in $\beta$-phase field. Moreover, the processing maps at the strain of $0.2,0.4,0.6$ and 0.8 were developed based on dynamic materials model (DMM). To deeply understand the microstructure evolution mechanism during hot deformation processes and to verify the processing maps, the microstructures at different deformation conditions were observed. The stable microstructures (i.e. globularization, dynamic recovery (DRV) and $\beta$ dynamic recrystallization ( $\beta$-DRX)) and instable microstructures (i.e. lamellae kinking and flow localization) were obtained. To make it useful in the design of industrial hot working schedules for this material, a microstructural mechanism map was constructed on the basis of processing maps and microstructure observation. Deformation conditions in the vicinity of $1150 \mathrm{~K} \& 0.01 \mathrm{~s}^{-1}$ where globularization occurs and in the vicinity of $1323 \mathrm{~K} \& 0.01$ $\mathrm{s}^{-1}$ where $\beta$-DRX occurs are recommended.
\end{abstract}

Keywords: Ti-6Al-4V-0.1Ru alloy, Hot compression test, Dynamic materials model, Processing map, Microstructural mechanism map

\section{Introduction}

Ti-6Al-4V-0.1Ru is a kind of $(\alpha+\beta)$ titanium alloy which is widely used in the field of energy and chemical processing industries because of its high corrosion resistance, excellent mechanical properties and low density etc. Generally, required components are manufactured by hot plastic deformation to get desired mechanical properties. As concluded by Quan et al. ${ }^{1}$ and Zhang et al. ${ }^{2}$, the usability and mechanical properties of products are determined by the microstructures of the material. Thus, to obtain better mechanical properties, it is of great importance to deeply understand the microstructural evolution mechanism during hot deformation. Shu et al. ${ }^{3}$ studied the hot deformation behaviours of as-forged Nitinol 60 alloy and found that deformation parameters such as strain rate and deformation temperature have an enormous effect on final microstructure, the researches by Quan et al. ${ }^{4}$ and Srinivasan et al. ${ }^{5}$ support their study. In other words, hot deformation behaviours affect the mechanical properties and service performances of the final products. Therefore, it is very valuable to investigate the relationships between deformation parameters and microstructural evolution mechanisms. It is a common belief that processing map is a very beneficial method to combine the microstructural evolution mechanism with deformation temperature, strain rate and strain. Processing map is a method which can track the microstructural evolution mechanism intuitively and precisely. By using processing maps, Wang et al. ${ }^{6}$ characterized the hot workability of AA 7050 aluminum alloy and Quan et al. ${ }^{7}$ identified the optimal working parameters of as-extrude $42 \mathrm{CrMo}$ high-strength steel.

The dynamic materials model (DMM) was firstly proposed on the fundamental principles of continuum mechanics of large plastic flow by Prasad et al. ${ }^{8}$, and its variant was carried out by Murty et al. ${ }^{9}$. Jenab and Karimi Taheri ${ }^{10}$ compared conventional DMM with flow localization parameter and enhanced DMM in the study of the hot deformation behaviour of AA7075 alloy. Saxena et al. ${ }^{11}$ made the comparative study using different materials model to delineate the safe and unsafe hot deformation parameters and found that DMM is the most appropriate to delineate different deformation conditions for $\mathrm{Zr}-2.5 \mathrm{Nb}$ alloy. As concluded by Quan et al. ${ }^{12}$, processing map based on DMM model has been widely used to obtain the stable and instable regions, optimize the deformation parameters, and control microstructures of alloys. Prasad and $\mathrm{Rao}^{13}$ developed the processing maps of electrolytic tough pitch copper based on DMM and applied standard kinetic analysis to evaluate the rate controlling mechanisms. Anbuselvan and Ramanathan ${ }^{14}$ identified the DRX and instability zones of ZE41A magnesium alloy by processing maps on the basis of DMM, which were validated through micrographs. 
Meanwhile, Lin et al. ${ }^{15}$ and Zhou et al. ${ }^{16}$ believed that constitutive relations can be established to describe the hot deformation behaviours of alloys. The constitutive analysis of the hot deformation behaviour based on Sellars-Tagart-Garofalo equation has been carried out on $\mathrm{Fe}-23 \mathrm{Mn}-2 \mathrm{Al}-0.2 \mathrm{C}$ twinning induced plasticity steel by Zhang et al. ${ }^{17}$. Lin et al. ${ }^{18}$ proposed a revised Arrhenius-type model to describe the flow behaviour of $42 \mathrm{CrMo}$ steel considering the effects of strain on material constants. The modified Zerilli-Armstrong models were successfully developed to predict hot deformation behaviour of 20CrMo alloy steel by He et al. ${ }^{19}$. Also, Yang et al. ${ }^{20}$ established a constitutive model of low carbon bainitic steel.

In this paper, the $\beta$ transus of Ti-6Al-4V-0.1Ru alloy was determined firstly by continuous heating method. The hot deformation behaviours of this alloy were investigated by the flow stress curves analysis, kinetic analysis and the processing maps based on DMM. The microstructures at different deformation conditions (temperatures and strain rates) were observed to validate the processing maps. On the basis of microstructure observation and processing maps, different microstructure mechanisms were identified and a microstructural mechanism map was developed. Eventually, optimized hot deformation parameters were recommended.

\section{Materials and experimental procedures}

The as-received material of this work is cold-rolled titanium alloy Ti-6Al-4V-0.1 Ru which is a kind of $(\alpha+\beta)$ titanium alloy with chemical compositions of $\mathrm{Fe} \leq 0.25, \mathrm{C}$ $\leq 0.08, \mathrm{~N} \leq 0.03, \mathrm{H} \leq 0.015, \mathrm{O} \leq 0.13, \mathrm{Al}: 5.5 \sim 6.5, \mathrm{~V}: 3.5 \sim 4.5$, $\mathrm{Ru}: 0.08 \sim 0.14$ (wt\%). The specimen was hot treated for homogenization and machined into cylinder with a diameter of $8 \mathrm{~mm}$ and a height of $12 \mathrm{~mm}$ by wire-electrode cutting. The microstructure of the specimen after hot treatment is illustrated in Figure 1. To determine the $\beta$ transus, three specimens were heated to 1188,1198 and $1208 \mathrm{~K}$ respectively and water quenched, after which, the microstructures of them were observed. The couple-thermal was weld on the both end faces of the specimen where were coated by a special high temperature lubricant. The temperatures of the specimens were elevated to $1023-1423 \mathrm{~K}$ with an interval of $50 \mathrm{~K}$ by $10 \mathrm{Ks}^{-1}$ respectively and kept for 180 $\mathrm{s}$, then the hot compression tests were carried out on a Gleeble-3500 isothermal simulator with the strain rate of $0.01,0.1,1,10 \mathrm{~s}^{-1}$ respectively with height reductions of $60 \%$. All specimens were water quenched to keep the microstructures after deformation. For the microstructure observation, the deformed specimens were sectioned perpendicular to the deformation axis and the cut faces were special treated.

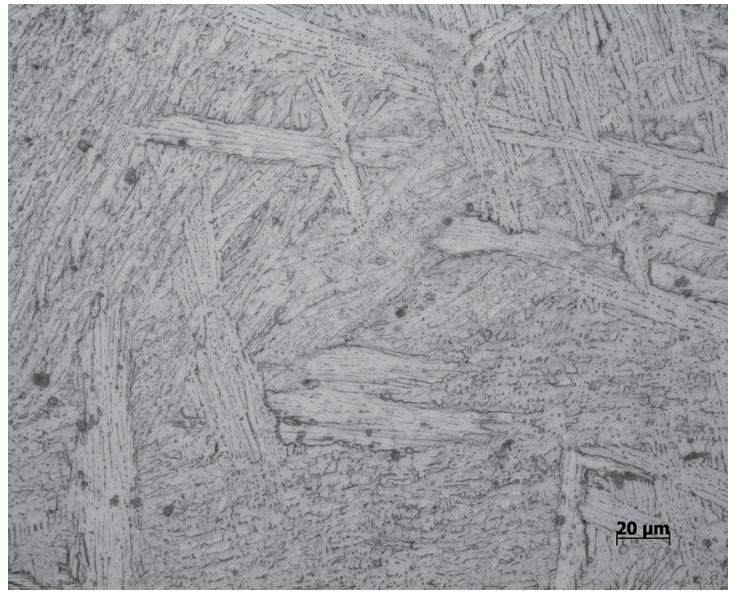

Figure 1: Microstructure of Ti-6Al-4V-0.1Ru titanium alloy after hot treatment

\section{Results and discussion}

\subsection{Determination of $\beta$ transus}

For the further research of Ti-6Al-4V-0.1Ru, the $\beta$ transus was determined by continuous heating method. Figure 2 shows the quenched microstructures of Ti-6Al-4V-0.1Ru at the temperatures of 1188,1198 and $1208 \mathrm{~K}$. It can be seen in Figure 2 (a), lamellae $\alpha$-grains distribute intensively on $\beta$-grains base. In Figure 2 (b), it is very obviously that the $\beta$-grains between two lamellae $\alpha$-grains were broadened, which indicates the beginning of the phase transformation. In Figure 2 (c), few lamellae $\alpha$-grains can be observed, which means that the phase transformation has almost completed. As a result, the $\beta$ transformation temperature range is 1188$1208 \mathrm{~K}$, to facilitate the calculation in following pages, the average value $1198 \mathrm{~K}$ was determined to be the $\beta$ transus.

\subsection{Flow curves}

The true strain-stress curves at different deformation temperatures and strain rates were illustrated in Figure 3. It can be seen that the flow stress increases dramatically at the initial stage, which is commonly believed that work hardening predominates. Due to the interaction of working hardening and dynamic softening, each flow curve ascends gradually to the peak at a certain strain and a gradual steady state occurs. Subsequently, it decreases slowly with the increasing of strain, which is believed that dynamic softening predominates. In addition, temperature, strain and strain rate influence the flow stress obviously and the flow stress increases with the rising of strain rate and decrease with the rising of temperature. Besides, some features can be observed as well: (a) where the deformation temperatures are lower than $\beta$ transus, each flow curve has a peak and an obvious reduction with the increase of strain, which suggests that dynamic recrystallization 

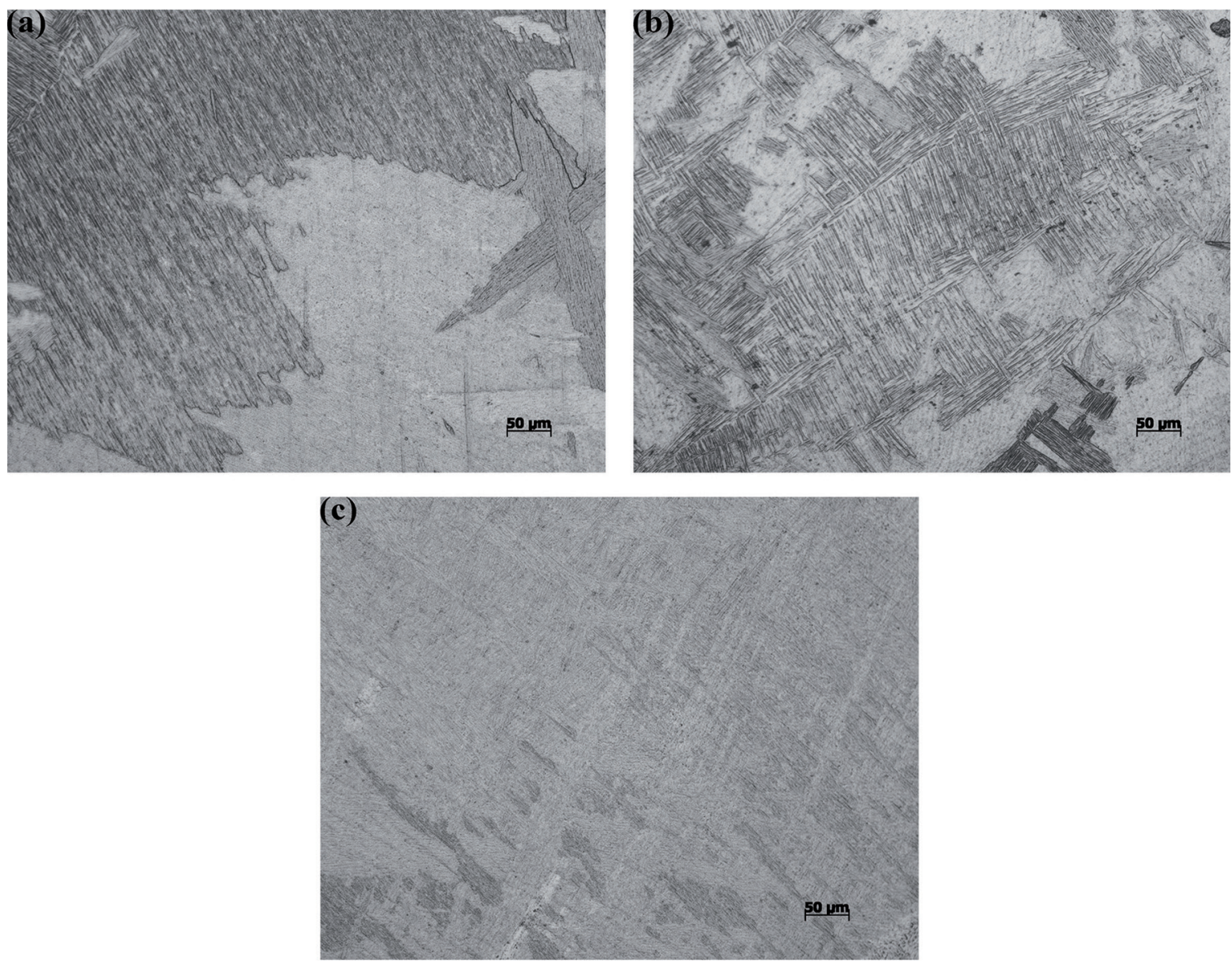

Figure 2: Microstructures of Ti-6Al-4V-0.1Ru at the temperatures of (a) $1188 \mathrm{~K}$; (b) $1198 \mathrm{~K}$ and (c) $1208 \mathrm{~K}$.

(DRX) is the primary deformation mechanism; (b) where the deformation temperatures are higher than $\beta$ transus, the flow curves without any peak reveal that dynamic recovery (DRV) is the primary deformation mechanism.

\subsection{Kinetics analysis based on Arrhenius-type equation}

The relationship of temperature, strain rate and strain during high temperature deformation is generally expressed by the Arrhenius-type equations as following ${ }^{17,21-22}$ :

$$
\begin{gathered}
\dot{\varepsilon} \exp (Q / R T)=A_{1} \sigma^{n_{1}} \\
\dot{\varepsilon} \exp (Q / R T)=A_{2} \exp (\beta \sigma) \\
\dot{\varepsilon} \exp (Q / R T)=A[\sinh (\alpha \sigma)]^{n}
\end{gathered}
$$

where $\dot{\varepsilon}$ is the strain rate, $R$ is the gas constant, $T$ is the absolute temperature, $Q$ is the activation energy for deformation, $\alpha\left(\approx \beta / n_{1}\right)^{23}, \beta, A, n_{1}$ and $n$ are material constants. The value of $Q$ is deemed to be an important parameter which indicates the intrinsic microstructural mechanism during hot deformation to some extent.
To investigate the effect of material constants on microstructural mechanism, the value of $Q, \alpha, A$, and $n$ at the particular true strain of 0.3 were calculated by following evaluation procedures. Taking natural logarithm of Eq. (3), following expression can be obtained:

$\ln \dot{\varepsilon}=\ln A+n \ln (\sinh (\alpha \sigma))-(Q / R T)$

For the further calculation of $Q$-value, the value of constant $\alpha$ should be obtained first. The following derived expression is widely used for the $\alpha$-value calculation ${ }^{23}$ :

$$
\alpha \approx \partial \ln \sigma / \partial \ln \dot{\varepsilon} /(\partial \sigma / \partial \ln \dot{\varepsilon})
$$

Figure 4 shows the plots of linear fitting of $\ln \sigma$ versus $\ln \dot{\varepsilon}$ at low stress level and $\sigma$ versus $\ln \dot{\varepsilon}$ at high stress level. The slope value of each line in Figure 4 (a) is the result of $\beta=\partial \ln \sigma / \partial \ln \dot{\varepsilon}$ and the slope value of each line in Figure 4 (b) is the result of $n_{1}=\partial \sigma / \partial \ln \sigma \dot{\varepsilon}$. The average value of $\beta$ and the average value of $n_{1}$ were used to calculate the result of Eq. (5), namely the value of $\alpha$. It can be seen in Figure 3, at the strain of 0.3, the tendency of each flow curve in the dual-phase field differs from 
(a)

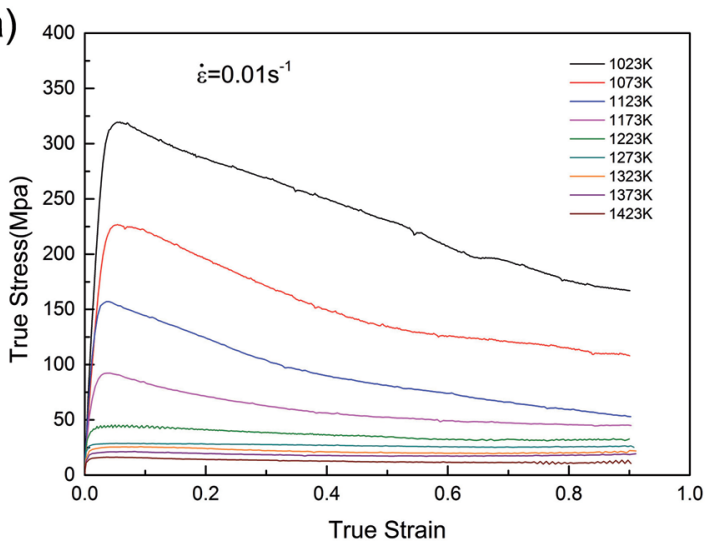

(c)

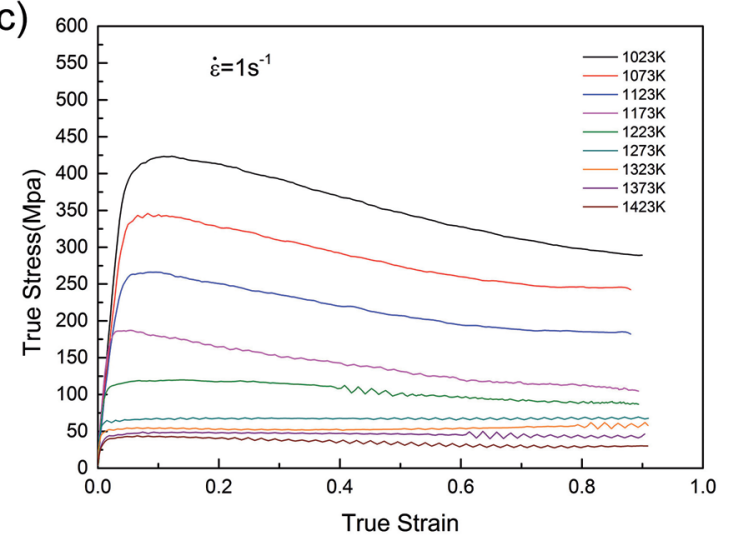

(b)

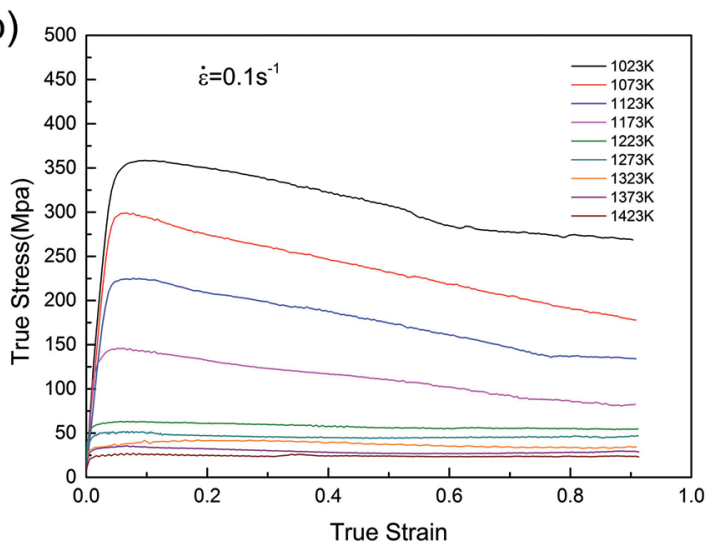

(d)

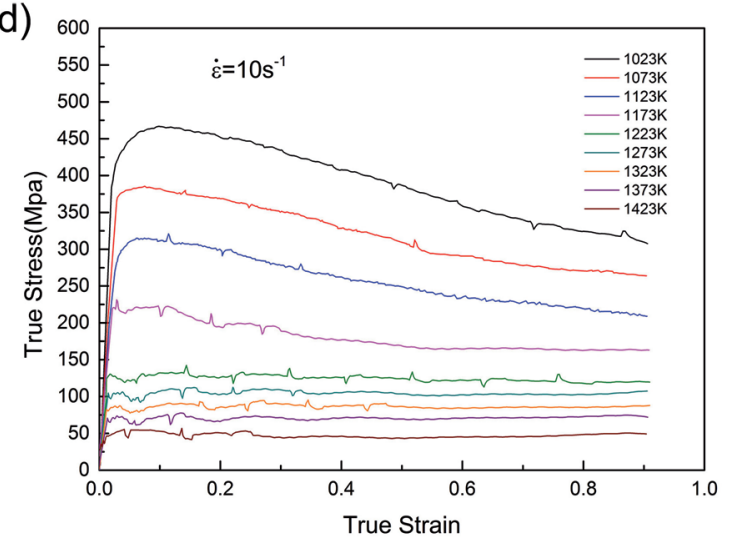

Figure 3: The true strain-stress curves of titanium alloy Ti-6Al-4V-0.1Ru at different temperatures and strain rates: (a) $\dot{\varepsilon}=0.01 \mathrm{~s}^{-1}$; (b) $\dot{\varepsilon}$ $=0.1 \mathrm{~s}^{-1} ;$ (c) $\dot{\varepsilon}=1 \mathrm{~s}^{-1} ;$ (d) $\dot{\varepsilon}=10 \mathrm{~s}^{-1}$.

(a)

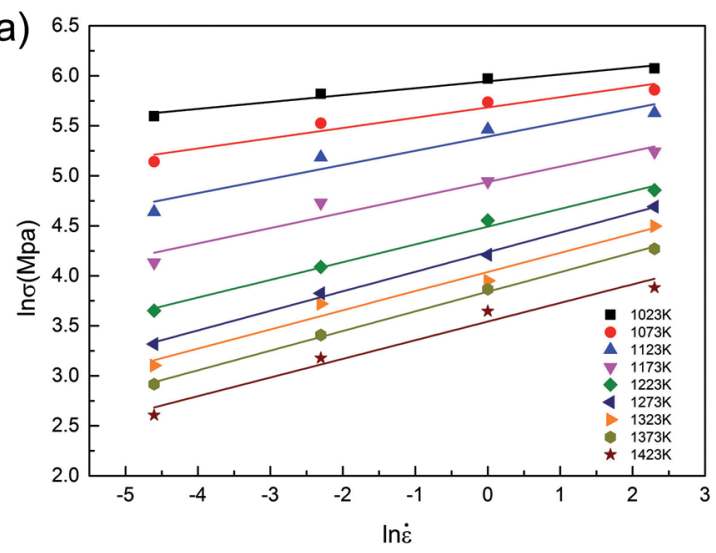

Figure 4: Plots of (a) $\ln \sigma$ versus $\ln \dot{\varepsilon}$, and (b) $\sigma$ versus $\ln \dot{\varepsilon}$.

that in $\beta$-phase field the most. This phenomenon reveals that the great differences of microstructure mechanism in different phase fields. Thus, we select stresses at the particular strain of 0.3 to determine the $Q$-value. Here, the value of $\alpha$ at the strain of 0.3 can be determined as $0.0052807 \mathrm{MPa}^{-1}$ in dual-phase field and 0.0225252 $\mathrm{MPa}^{-1}$ in $\beta$-phase field.

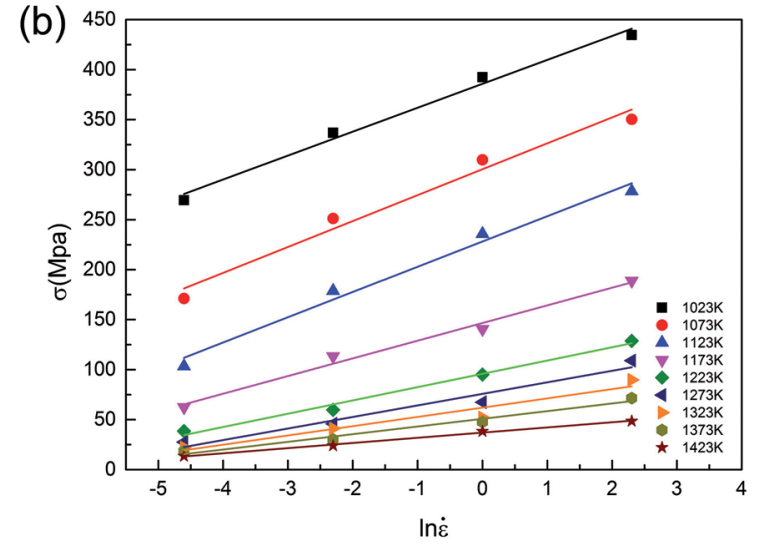

Based on the experiment data, the $Q$-value was calculated by the following expression ${ }^{20}$ :

$$
Q=1000 R n K_{2}=\left.R n \frac{\partial \ln [\sin (\alpha \sigma)]}{\partial(1 / T)}\right|_{\dot{\varepsilon}}
$$

Where $R$ is the gas constant, $\mathrm{n}=1 / \mathrm{K}_{1}$ and the expressions of $\mathrm{K}_{1}$ and $\mathrm{K}_{2}$ are shown as following: 


$$
\begin{gathered}
K_{1}=\left.\frac{\partial \ln [\sin (\alpha \sigma)]}{\partial \ln \dot{\varepsilon}}\right|_{T} \\
K_{2}=\left.\frac{1}{1000} \cdot \frac{\partial \ln [\sin (\alpha \sigma)]}{\partial(1 / T)}\right|_{\dot{\varepsilon}}
\end{gathered}
$$

The values of $\mathrm{K}_{1}$ and $\mathrm{K}_{2}$ are the average slopes of plots of $\ln \dot{\varepsilon}$ versus $\ln (\sinh (\alpha \sigma))$ and $\ln (\sinh (\alpha \sigma))$ versus $(1000 / \mathrm{T})$ respectively as shown in Figure 5 (a), (b) and (c). Here, the deformation activation energy at the strain of 0.3 were determined to be $630.01 \mathrm{~kJ} / \mathrm{mol}$ in dual-phase field and 331.75 $\mathrm{kJ} / \mathrm{mol}$ in $\beta$-phase field. Compared with the self-diffusion activation energy in $\alpha$-Ti $(169 \mathrm{~kJ} / \mathrm{mol})$ and $\beta$-Ti $(153 \mathrm{~kJ} /$ mol) reported by Seshacharyulu et al. ${ }^{24}$, the deformation activation energy above are higher ruling out the possibility of diffusion being the dominate rate controlling process. Due to the elevation of activation energy during nucleation or crystallization processes, the higher deformation activation energy in dual-phase field may be induced by the deformation mechanism such as globularization or DRX of lamellar $\alpha$-grains. On the other hand, the lower deformation activation energy in $\beta$-phase field may reveal that DRV predominates. In addition, bcc lattice of $\beta$-Ti has more slip systems and higher diffusion coefficient than hep lattice of $\alpha$-Ti, which causes the deformation activation energy in dual-phase field higher than that in $\beta$-phase field.

The Zener-Hollom parameter $(Z)$ in an exponent-type equation as shown in Eq. (9) is introduced to represent the effects of temperature and strain rate on hot deformation behaviours.

$$
Z=\dot{\varepsilon} \exp (Q / R T)
$$

According to Eq. (3) and Eq. (9), the values of $n$ and constant $A$ are determined to be 3.440097 and $1.02789 \times 10^{12}$ $\mathrm{s}^{-1}$ in dual-phase field and 5.154922 and $4.49675 \times 10^{27} \mathrm{~s}^{-1}$ in $\beta$-phase field by linear fitting of $\ln Z$ versus $\ln (\sinh (\alpha \sigma))$ as shown in Figure 5 (d). The linear relationship of $\ln Z$ versus $\ln (\sinh (\alpha \sigma))$ with a correlation coefficient $(\mathrm{R})$ of 0.993 in dual-phase field and 0.985 in $\beta$-phase field respectively reflects a good predication capability of hyperbolic sine function for both phase fields.

\subsection{Strain rate sensitivity}

Strain rate sensitivity $(m)$ of flow stress is a very important parameter which reveals the ductility and plastic of metals and alloys in the forming processes. According to Prasad et al. ${ }^{8}$, the strain rate sensitivity index $m$ is denoted as:

$$
m=\left(\frac{\partial \ln \sigma}{\partial \ln \dot{\varepsilon}}\right)_{T, \varepsilon} \approx\left(\frac{\Delta \log \sigma}{\Delta \log \dot{\varepsilon}}\right)_{T, \varepsilon}
$$

The fitted cubic spines for $\log \sigma$ versus $\log \dot{\varepsilon}$ at different deformation temperatures and strains are shown in Figure 6.
As concluded by Luo et al. ${ }^{25}$, the relationship between $\log \sigma$ and $\log \dot{\varepsilon}$ is expressed as:

$$
\log \sigma=a+b \log \dot{\varepsilon}+c(\log \dot{\varepsilon})^{2}+d(\log \dot{\varepsilon})^{3}
$$

The $m$-value is evaluated as a function of strain rate and is written as:

$$
\begin{aligned}
& m=d(\log \sigma) / d(\log \dot{\varepsilon})= \\
& b+2 c \log \dot{\varepsilon}+3 d(\log \dot{\varepsilon})^{2}
\end{aligned}
$$

The constants $b, c$ and $d$ were obtained by the fitted cubic spines for $\log \sigma$ versus $\log \dot{\varepsilon}$. Here, the $m$-values at different deformation conditions were calculated as show in Table 1 and the 3D response surfaces of $m$-values were illustrated in Figure 7. From Figure 7, it can be seen that $m$-values vary violently with the variation of temperatures, strains and strain rates, which indicates that microscopic deformation mechanism has been changed greatly. Besides, a negative $m$-value occurs at the deformation condition of $1423 \mathrm{~K} \& 1_{10 \mathrm{~s}^{-1}}$ as shown in Table 1. Prasad ${ }^{26}$ believes that negative $m$-values are usually obtained under the conditions that promote dynamic strain aging (DSA), deformation twinning, shear band formation, or initiation and growth of microcracks. However, the category of microstructural defects cannot be identified by negative $m$-values. Due to the coexistence and cooperation of various microstructural mechanisms, it can hardly indicate that the deformation conditions are under stable regions even if $m$-values are positive. Furthermore, Ti-6Al-4V-0.1Ru is a kind of $(\alpha+\beta)$ titanium alloy whose phase transformation and variation of grains are more complicated than single phase materials. Thus, the 3D response surfaces of $m$-values only reveal the dynamic balance variation of microstructure during hot deformation. To identify the microstructure evolution and defects, processing maps need to be developed.

\subsection{Processing maps}

According to DMM by Prasad et al. ${ }^{8}$, the deformation process is considered as a nonlinear power dissipation process. The total power $(P)$ consists of the power dissipated by plastic deformation $(G)$ and the power dissipated by microstructure evolution $(J)$. The $G$ term represents the power dissipated by plastic work, most of which is converted into heat. The remaining small part is stored as lattice defects. The dissipater power co-content $J$ is related to the metallurgical mechanisms which occur dynamically to dissipate power. The dependence of $P, G$ and $J$ is denoted as:

$$
P=\sigma \cdot \dot{\varepsilon}=G+J=\int_{0}^{\dot{\varepsilon}} \sigma d \dot{\varepsilon}+\int_{0}^{\sigma} \dot{\varepsilon} d \sigma
$$


(a)
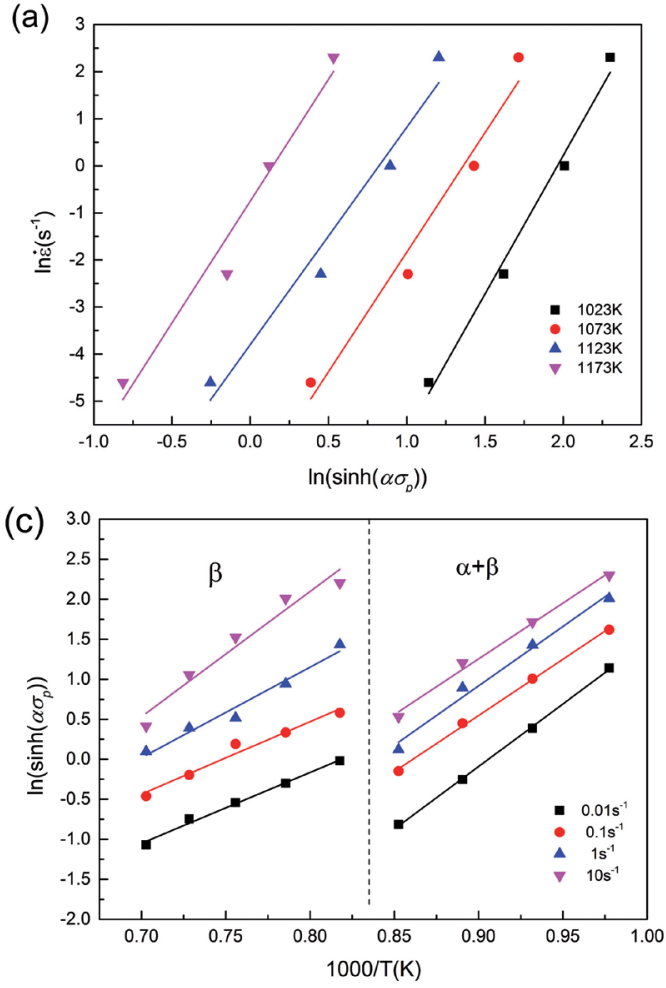

(b)

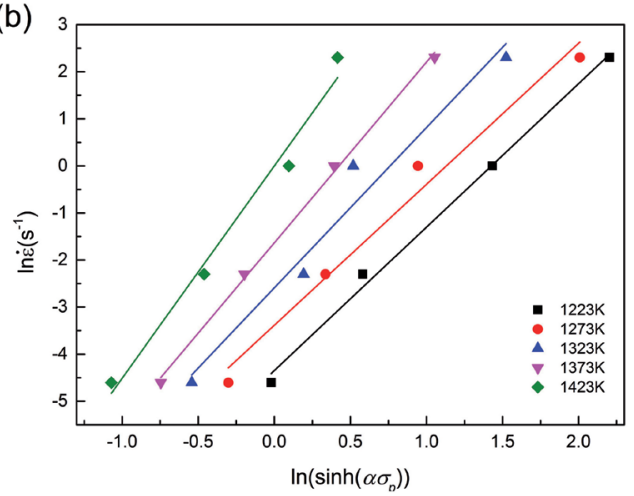

(d)

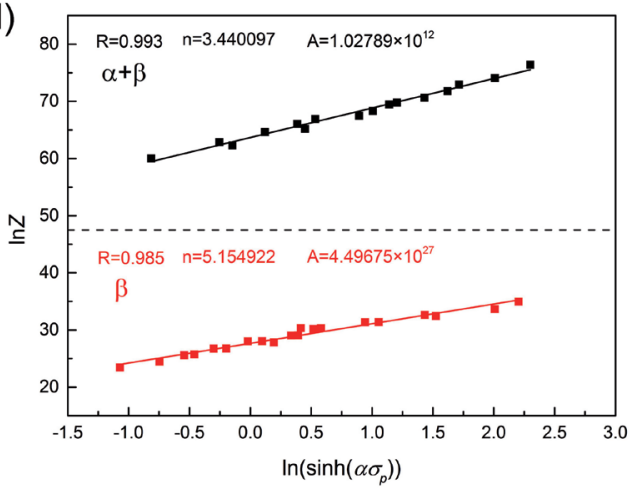

Figure 5: Plots of (a) $\ln \dot{\varepsilon}$ versus $\ln (\sinh (\alpha \sigma))$ in dual-phase field, (b) $\ln \dot{\varepsilon}$ versus $\ln (\sinh (\alpha \sigma))$ in $\beta$-phase field, (c) (1000/T) versus $\ln (\sinh (\alpha \sigma))$ and $(\mathrm{d}) \ln (\sinh (\alpha \sigma))$ versus $\ln Z$.

(a)

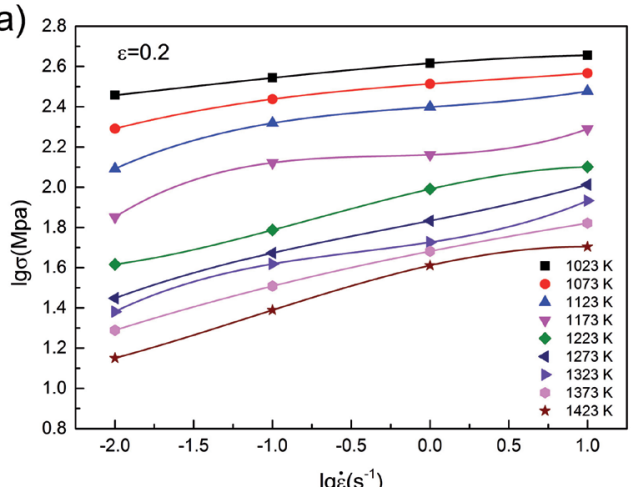

(c)

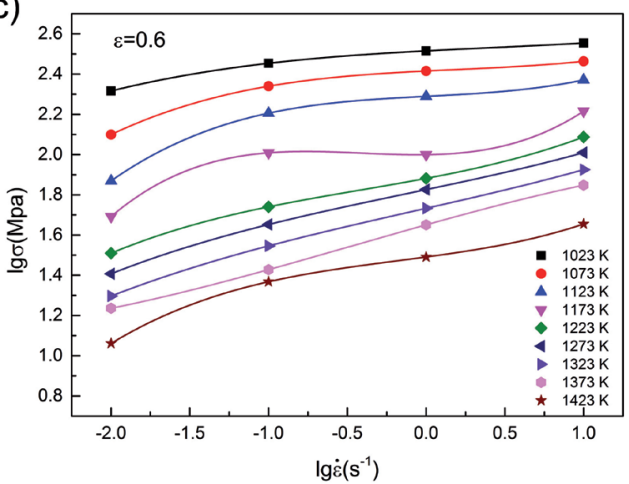

(b)

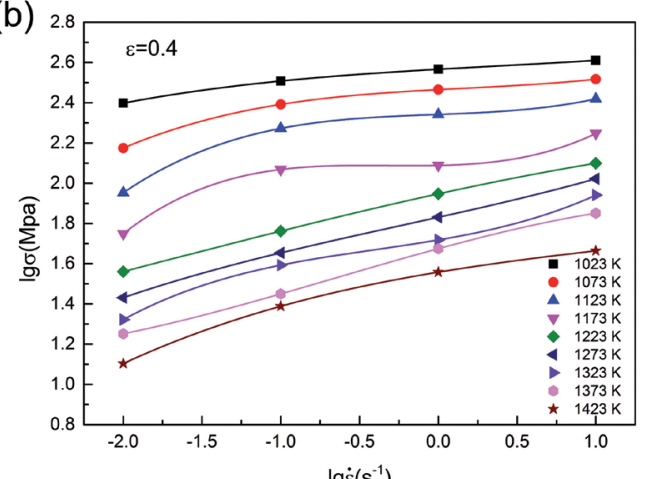

(d)

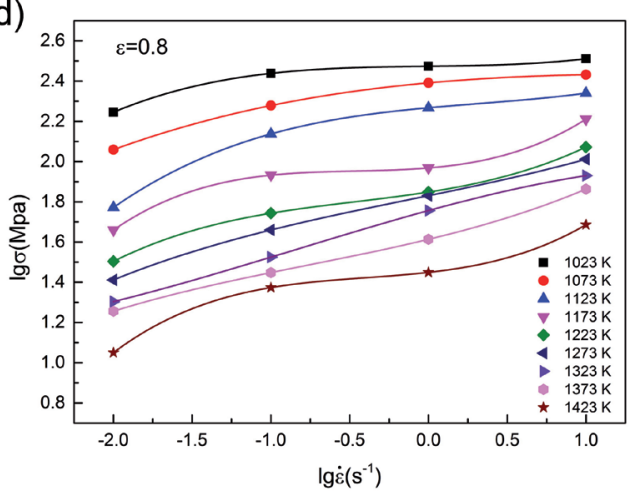

Figure 6: The relationships between stress and strain rate in log scale at different deforming temperatures and true strains (a) $\varepsilon=0.2$, (b) $\varepsilon=0.4,(\mathrm{c}) \varepsilon=0.6$ and $(\mathrm{d}) \varepsilon=0.8$. 
Table 1: $m$-values at different temperatures, strains and strain rates.

\begin{tabular}{|c|c|c|c|c|c|c|c|c|c|c|}
\hline \multirow{2}{*}{ strain } & \multirow{2}{*}{$\begin{array}{c}\text { Strain } \\
\text { rate }\left(\mathrm{s}^{-1}\right)\end{array}$} & \multicolumn{9}{|c|}{ Temperature (K) } \\
\hline & & 1023 & 1073 & 1123 & 1173 & 1223 & 1273 & 1323 & 1373 & 1423 \\
\hline \multirow{4}{*}{0.2} & 0.01 & 0.0863 & 0.1985 & 0.3486 & 0.4921 & 0.1133 & 0.2865 & 0.3766 & 0.2462 & 0.2099 \\
\hline & 0.1 & 0.0826 & 0.1032 & 0.1291 & 0.1014 & 0.2083 & 0.1785 & 0.1347 & 0.1946 & 0.2489 \\
\hline & 1 & 0.0592 & 0.0563 & 0.0552 & 0.0306 & 0.1778 & 0.1554 & 0.1196 & 0.1545 & 0.1762 \\
\hline & 10 & 0.0160 & 0.0576 & 0.1268 & 0.2799 & 0.0218 & 0.2172 & 0.3313 & 0.1261 & -0.0082 \\
\hline \multirow{4}{*}{0.4} & 0.01 & 0.1480 & 0.3297 & 0.5314 & 0.6146 & 0.2044 & 0.2660 & 0.4236 & 0.1593 & 0.3597 \\
\hline & 0.1 & 0.0779 & 0.1248 & 0.1514 & 0.0967 & 0.1963 & 0.1899 & 0.1579 & 0.2244 & 0.2183 \\
\hline & 1 & 0.0451 & 0.0421 & 0.0301 & 0.0167 & 0.1714 & 0.1741 & 0.1337 & 0.2134 & 0.1293 \\
\hline & 10 & 0.0496 & 0.0817 & 0.1673 & 0.3746 & 0.1297 & 0.2184 & 0.3512 & 0.1262 & 0.0930 \\
\hline \multirow{4}{*}{0.6} & 0.01 & 0.1932 & 0.3692 & 0.5466 & 0.6640 & 0.3277 & 0.3085 & 0.3038 & 0.1576 & 0.4734 \\
\hline & 0.1 & 0.0909 & 0.1350 & 0.1682 & 0.0617 & 0.1604 & 0.1958 & 0.2070 & 0.2172 & 0.1774 \\
\hline & 1 & 0.0415 & 0.0389 & 0.0408 & 0.0115 & 0.1477 & 0.1650 & 0.1782 & 0.2196 & 0.1062 \\
\hline & 10 & 0.0450 & 0.0810 & 0.1644 & 0.5134 & 0.2895 & 0.2161 & 0.2173 & 0.1649 & 0.2596 \\
\hline \multirow{4}{*}{0.8} & 0.01 & 0.3253 & 0.2842 & 0.5429 & 0.5391 & 0.3917 & 0.3169 & 0.1926 & 0.2412 & 0.5838 \\
\hline & 0.1 & 0.0875 & 0.1602 & 0.2181 & 0.0803 & 0.1303 & 0.1948 & 0.2381 & 0.1605 & 0.1312 \\
\hline & 1 & 0.0096 & 0.0709 & 0.0715 & 0.0653 & 0.1221 & 0.1610 & 0.2142 & 0.1894 & 0.0881 \\
\hline & 10 & 0.0916 & 0.0163 & 0.1031 & 0.4939 & 0.3672 & 0.2155 & 0.1210 & 0.3279 & 0.4546 \\
\hline
\end{tabular}

(a)

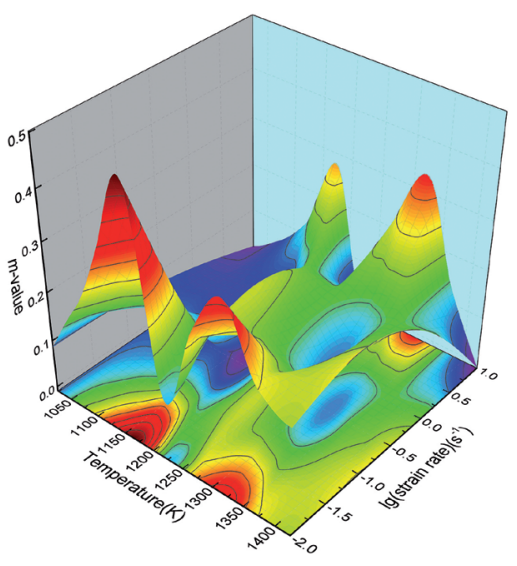

(c)

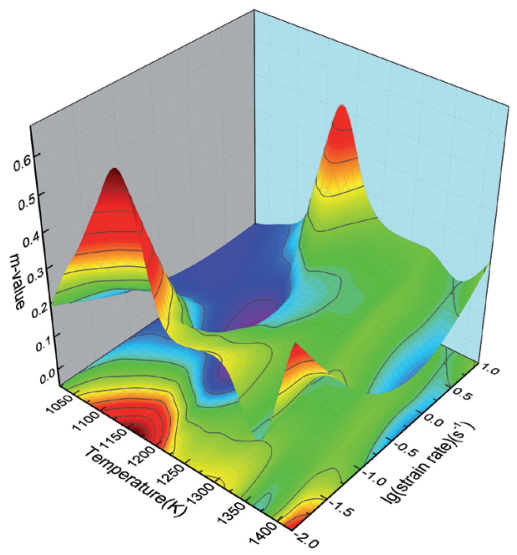

(b)

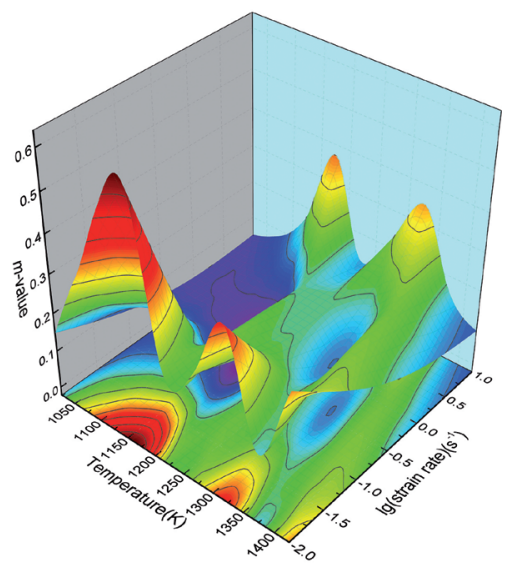

(d)

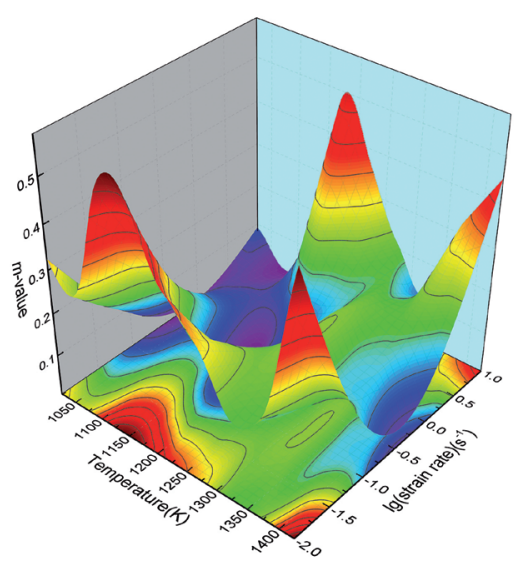

Figure 7: The 3D response surface of $m$-value on strain rate and temperature under different strains: (a) $\varepsilon=0.2$, (b) $\varepsilon=0.4$, (c) $\varepsilon=0.6$ and (d) $\varepsilon=0.8$. 
From Eq. (10), it also follows that the dynamic constitutive equation is of the type:

$$
\sigma=A \cdot \dot{\varepsilon}^{m}
$$

At a given temperature and strain rate, the $J$ co-content is determined as:

$$
J=\int_{0}^{\sigma} \dot{\varepsilon} d \sigma=\frac{m}{m+1} \sigma \dot{\varepsilon}
$$

Under the ideal linear dissipation condition, $J$ co-content reaches maximum value $J_{M A X}$ which is denoted as:

$$
J_{\text {MAX }}=\sigma \dot{\varepsilon} / 2 \quad(16)
$$

While the $m$-value varies non-linear with the temperature and strain rate during hot deformation process under normal conditions, a dimensionless parameter $(\eta)$ called power dissipation efficiency is obtained as:

$$
\eta=\frac{J}{J_{\mathrm{MAX}}}=\frac{2 m}{m+1}
$$

Different power dissipation efficiency $(\eta)$ responds to different microstructural evolution mechanism during hot deformation process. The variation of $\eta$-value with temperature and strain rate is exhibited by the power dissipation map. Generally, higher $\eta$-value means better performance of microstructure. Eq. (18) is the instability criterion $(\xi)$ as a function constructed by Prasad et al. ${ }^{27}$ based on the principle of maximum entropy generation rate built by Ziegler. The physical meaning of the instability criterion is that instability occurs when the strain rate of the whole deformation system is greater than the production rate of entropy inside the system. The variation of $\xi$-value with temperature and strain rate in a two-dimensional plane constitutes the instability map. In an instability map, instability defects appears in a specific region where the $\xi$-value is negative. Eventually, the overlap of the power dissipation map and the instability map constitutes the processing map.

$$
\xi(\dot{\varepsilon})=\frac{\partial \ln \frac{m}{m+1}}{\partial \ln \dot{\varepsilon}}+m<0
$$

By using processing map based on DMM, the relationship between microstructure evolution and power dissipation during hot deformation process was analyzed. The plastic processing area is divided into stable region and instable region. Generally, dynamic restoration mechanisms include DRV, DRX, globularization and superplastic occur in stable region. While such instability defects like cavities, grain boundary cracks, adiabatic shear bands, flow localization and deformation twinning occur in instable region where should be avoid during hot deformation. Thus, to obtain better intrinsic workability, deformation parameters (temperatures and strain rates) optimized by processing map could be applied in deformation process.

The processing maps of Ti-6Al-4V-0.1 Ru at the strain of $0.2,0.4,0.6,0.8$, strain rate range of $0.01-10 \mathrm{~s}^{-1}$ and temperature range of 1023-1423 $\mathrm{K}$ are illustrated in Figure 8 . The counter numbers in a processing map are power dissipation efficiency $(\eta)$. The areas in blue dashed boxes are stable regions (denoted as DOM) and the gray areas are instable regions (denoted as INST). It can be seen from Figure 8 (a), there are five stable regions at the strain of 0.2 : $\# 1: 1100-1205 \mathrm{~K} \& 0.01-0.035 \mathrm{~s}^{-1}$, and the peak $\eta$-value is about 0.61 ; \#2:1080-1200 K \& 1.778-10 s $\mathrm{s}^{-1}$, and the peak $\eta$-value is about 0.33 ; \#3:1205-1280 K \& $0.01-0.251 \mathrm{~s}^{-1}$, and the peak $\eta$-value is about $0.40 ; \# 4: 1265-1375 \mathrm{~K} \& 0.248-10$ $\mathrm{s}^{-1}$, and the peak $\eta$-value is about 0.33 ; \#5:1352-1423 $\mathrm{K} \&$ $0.01-0.501 \mathrm{~s}^{-1}$, and the peak $\eta$-value is about 0.40 . Figure 8 (b) shows the processing map at the strain of 0.4 , there are five stable regions as well: \#1: 1065-1190 K \& 0.01-0.039 $\mathrm{s}^{-1}$, and the peak $\eta$-value is about 0.71 ; $\# 2: 1090-1220 \mathrm{~K} \&$ $1.778-10 \mathrm{~s}^{-1}$, and the peak $\eta$-value is about 0.39 ; \#3:1210$1295 \mathrm{~K} \& 0.01-1.259 \mathrm{~s}^{-1}$, and the peak $\eta$-value is about 0.47 ; $\# 4: 1255-1370 \mathrm{~K} \& 0.251-10 \mathrm{~s}^{-1}$, and the peak $\eta$-value is about 0.47 ; \#5:1340-1423 K \& $0.01-0.251 \mathrm{~s}^{-1}$, and the peak $\eta$-value is about 0.40 . Figure 8 (c) shows the processing map at the strain of 0.6 , there are three stable regions: \#1: $1055-1165 \mathrm{~K} \& 0.01-0.018 \mathrm{~s}^{-1}$, and the peak $\eta$-value is about 0.73 ; \#2:1125-1423 K \& $1.995-10 \mathrm{~s}^{-1}$, and the peak $\eta$-value is about 0.56 ; \#3:1226-1405 $\mathrm{K} \& 0.01-1.995 \mathrm{~s}^{-1}$, and the peak $\eta$-value is about 0.47 . Figure 8 (d) shows the processing map at the strain of 0.8 , there are five stable regions: \#1: $1070-1140 \mathrm{~K} \& 0.01-0.020 \mathrm{~s}^{-1}$, and the peak $\eta$-value is about 0.67 ; \#2:1135-1300 K \& $0.631-10 \mathrm{~s}^{-1}$, and the peak $\eta$-value is about 0.57 ; \#3:1252-1365 $\mathrm{K} \& 0.01-1.995 \mathrm{~s}^{-1}$, and the peak $\eta$-value is about 0.51 ; \#4:1330-1423 K \& $0.501-10 \mathrm{~s}^{-1}$, and the peak $\eta$-value is about 0.57 .

\subsection{Microstructure observations}

To deeply understand the relationships between microstructures and deformation parameters, as well as verifying the stable and instable regions in processing maps, the typical microstructures of Ti-6Al-4V-0.1Ru at different deformation conditions were observed by optical microscopy. Figure 9 shows the microstructure of Ti-6Al-4V-0.1Ru at the strain rate of $0.01 \mathrm{~s}^{-1}$ and different deformation temperatures. The globularization of lamellae $\alpha$-grains and bulk $\beta$-grains can be observed at the temperature of $1023 \mathrm{~K}$ as shown in Figure 9 (a). Figure 9 (b)-(d) show the microstructures at the temperature of $1073 \mathrm{~K}, 1123 \mathrm{~K}, 1173 \mathrm{~K}$ (below $\beta$ transus) respectively, it can be seen that the globularization process become violent with the rising of temperature. In the processing 
(a)
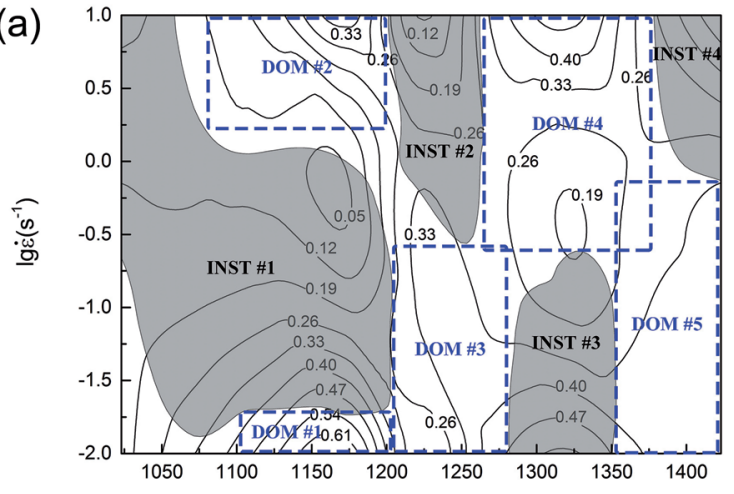

$\mathrm{T}(\mathrm{K})$

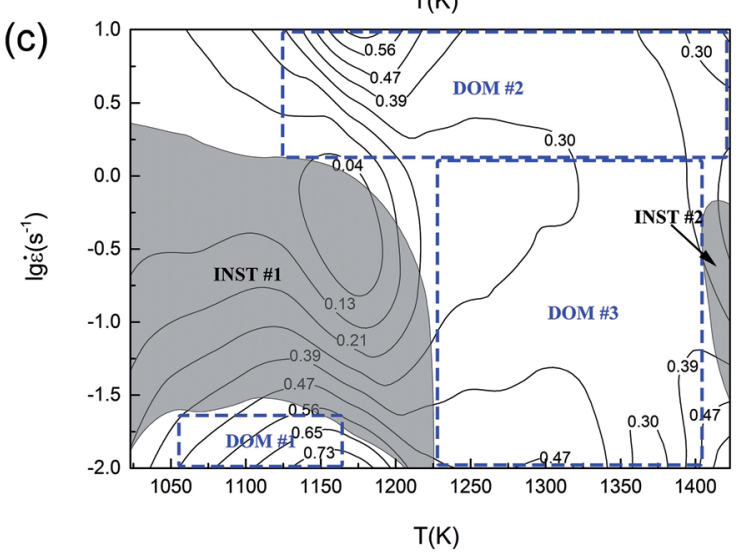

(b)

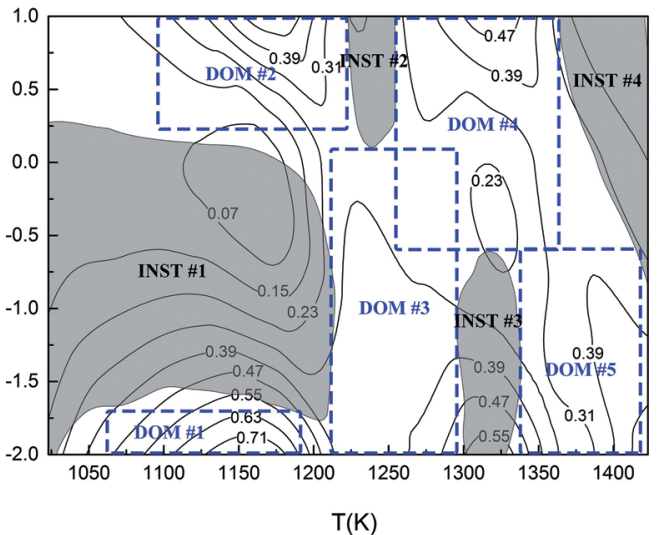

(d)
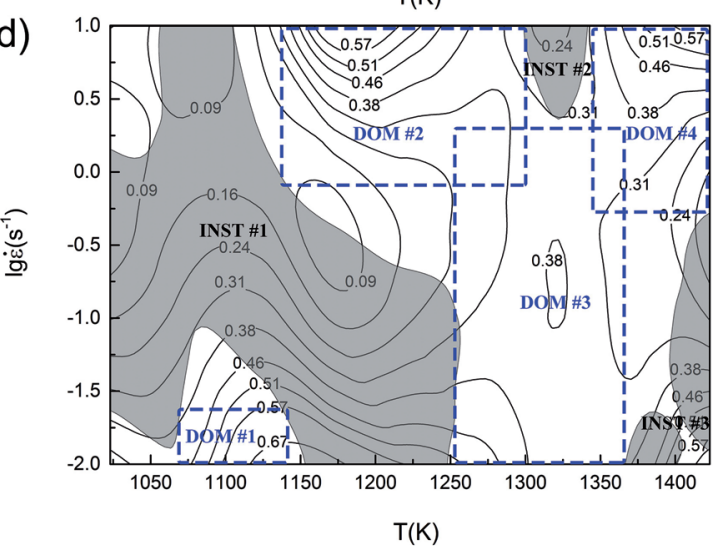

Figure 8: The processing map of Ti-6Al-4V-0.1Ru at the strain of (a) 0.2 ; (b) 0.4 ; (c) 0.6 ; (d) 0.8 .

maps shown in Figure 8, the $\eta$-values are about 0.19, 0.40, 0.54 and 0.61 at the corresponding deformation conditions where is marked as DOM \#1, which indicates that high power dissipation efficiency relates to violent globularization. The microstructures at the deformation conditions of 1273 $\mathrm{K} \& 0.01 \mathrm{~s}^{-1}$ and $1323 \mathrm{~K} \& 0.01 \mathrm{~s}^{-1}$ (above $\beta$ transus) are shown in Figure 9 (e) and (f). It can be seen in Figure 9 (e) (the deformation condition regions corresponding to DOM \#3 with the highest $\eta$-value of about 0.46 in processing maps), the grain boundaries of martensite grains are not clearly curved, which is attributed to DRV process during hot deformation. In Figure 9 (f) (the deformation condition regions corresponding to INST \#3 with the highest $\eta$-value of about 0.55 in processing maps at the strain of 0.2 and 0.4 ), there are no defect but some $\beta$-DRX grains can be observed, this phenomenon may be led by the restoration of defects and remain of $\beta$-DRX process with increasing strain.

Figure 10 shows the microstructures at the deformation conditions of $1073 \mathrm{~K} \& 1 \mathrm{~s}^{-1}, 1073 \mathrm{~K} \& 0.1 \mathrm{~s}^{-1}, 1123 \mathrm{~K} \& 1 \mathrm{~s}^{-1}$

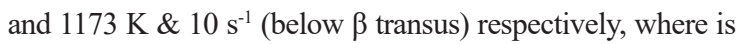
the instable region marked as INST \#1 in the processing maps, flow localization bands, lamellae kinking can be observed. According to Seshacharyulu et al. ${ }^{28}$, the adiabatic conditions created during deformation and low thermal conductivity may be the main reason for the formation of flow localization bands.
Besides, high strain rate made it difficult to conduct away the heat generated during hot deformation, which reduces flow stress locally and causes flow localization. The formation of lamellae kinking is probably due to mechanical instability (e.g. buckling) of the lamellae under compressive strains and can form in the colonies inclined up to $45^{\circ}$ to the compression axis.

\subsection{Microstructural mechanism map}

To make it useful in the design of industrial hot working schedules for this material, a microstructural mechanism map based on the experiment results and processing maps was developed as shown in Figure 11. Combining microstructures with processing maps, low strain rate region with the $\eta$-value higher than 0.33 in dual-phase field was determined to be globularization region. Moreover, lamellae kinking occurs at the region with the $\eta$-value range of $0.22-0.33$, and flow localization occurs at the region with the $\eta$-value lower than 0.22 in dual-phase field. In $\beta$-phase field, $\beta$-DRX occurs at the region with the $\eta$-value higher than 0.47 , and $\beta$-phase DRV occurs at the deformation condition of 1198-1360 $\mathrm{K} \& 0.01-0.708 \mathrm{~s}^{-1}$ excluding the $\beta$-DRX region. As a result, $1150 \mathrm{~K} \& 0.01 \mathrm{~s}^{-1}$ where globularization occurs and $1323 \mathrm{~K}_{0} 0.01 \mathrm{~s}^{-1}$ where $\beta$-DRX occurs are recommended deformation parameters. 

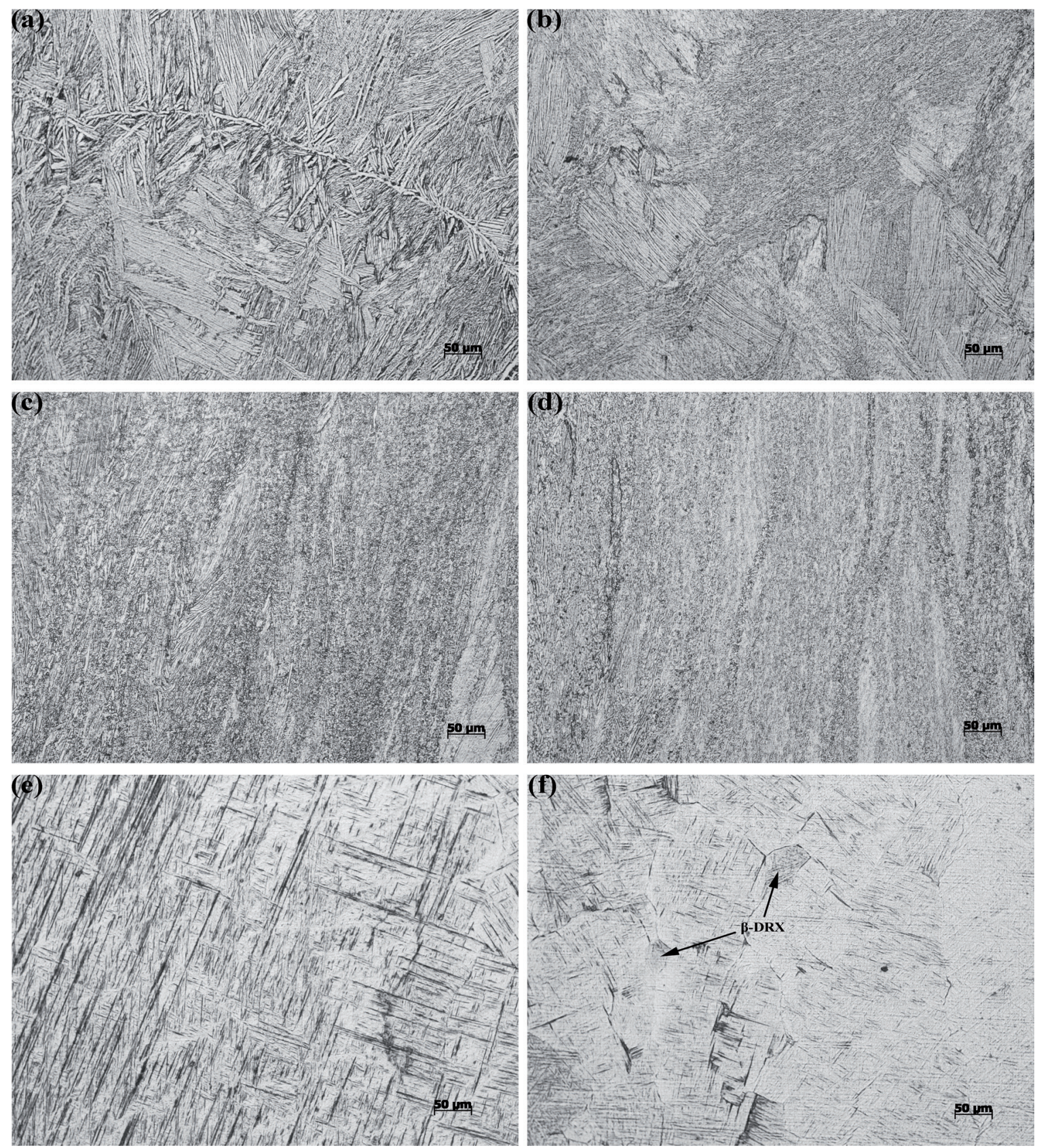

Figure 9: Microstructures of Ti-6Al-4V-0.1Ru at the strain of 0.9, strain rate of $0.01 \mathrm{~s}^{-1}$, and deformation temperatures of (a) $1023 \mathrm{~K}$; (b) $1073 \mathrm{~K}$; (c) $1123 \mathrm{~K}$; (d) $1173 \mathrm{~K}$; (e) $1273 \mathrm{~K}$ and (f) $1323 \mathrm{~K}$.

\section{Conclusions}

Hot compression testing of Ti-6Al-4V-0.1Ru alloy has been conducted in the temperature range 1023-1423 K and the strain rate range $0.01-10 \mathrm{~s}^{-1}$. The $\beta$ transus of this alloy has been determined, the kinetics equation was constructed, the processing maps and the microstructural mechanism map were developed. The following conclusions are drawn from this investigation.

(1) By continuous heating method and microstructure observation, the $\beta$ transus of Ti-6Al-4V-0.1Ru alloy was determined to be $1198 \mathrm{~K}$.
(2) The deformation activation energy of Ti- $6 \mathrm{Al}-4 \mathrm{~V}-0.1 \mathrm{Ru}$ alloy at the strain of 0.3 was calculated as $630.01 \mathrm{~kJ} /$ mol in dual-phase field and $331.75 \mathrm{~kJ} / \mathrm{mol}$ in $\beta$-phase field. Based on the results, the kinetic of microstructure mechanisms was analyzed. The effect of deformation parameters (temperature and strain rate) on flow stress can be described by the following equations:

In dual-phase field:

$Z=\dot{\varepsilon} \exp (630010 / R T)$

$=1.02789 \times 10^{12} \times[\sinh (0.00528 \sigma)]^{3.4001}$ 

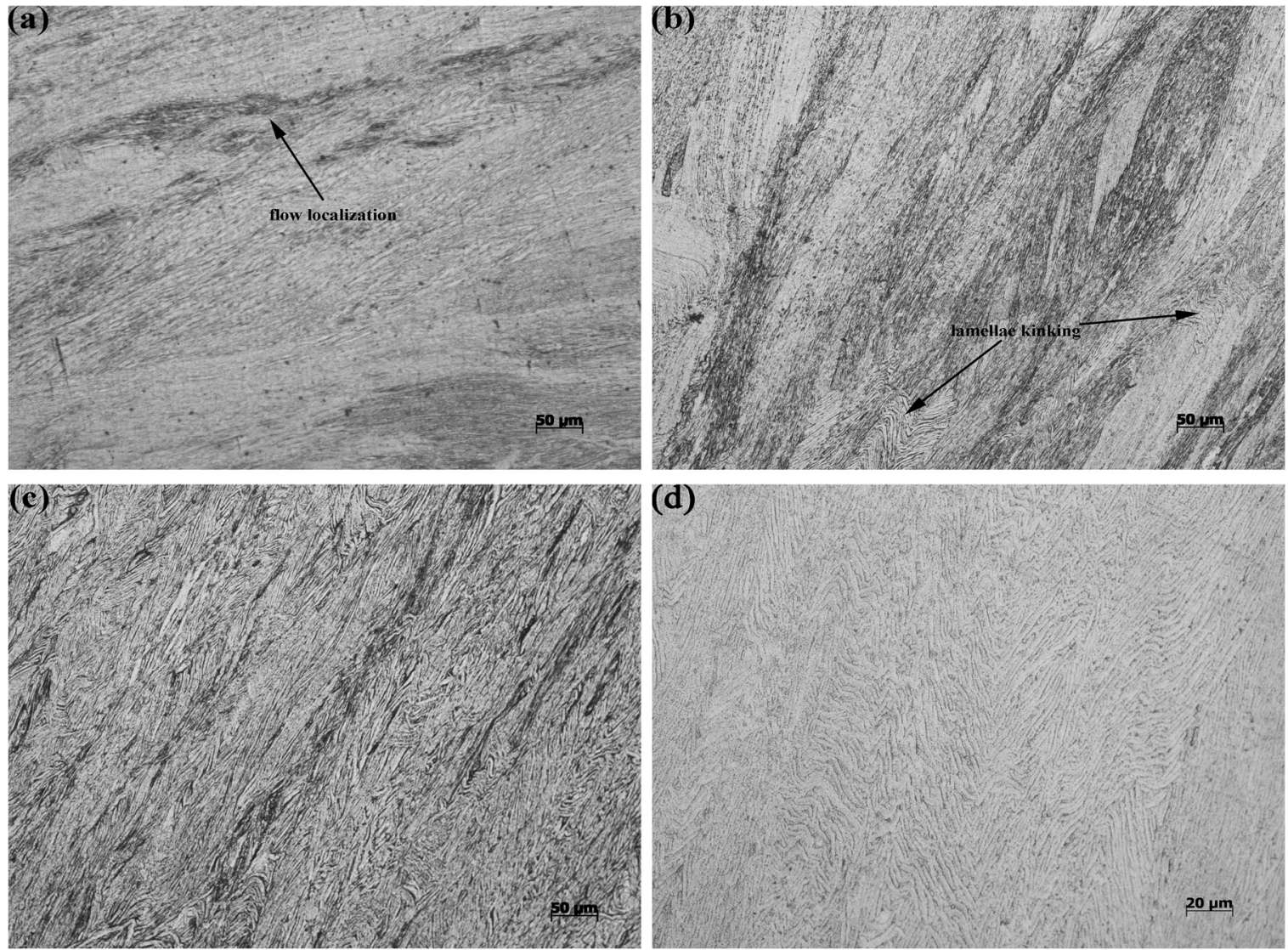

Figure 10: Microstructures of Ti-6Al-4V-0.1Ru at strain of 0.9 and the deformation conditions of (a) $1073 \mathrm{~K} \& 1 \mathrm{~s}^{-1}$; (b) $1073 \mathrm{~K} \& 0.1$ $\mathrm{s}^{-1}$; (c) $1123 \mathrm{~K} \& 1 \mathrm{~s}^{-1}$ and (d) $1123 \mathrm{~K} \& 10 \mathrm{~s}^{-1}$.

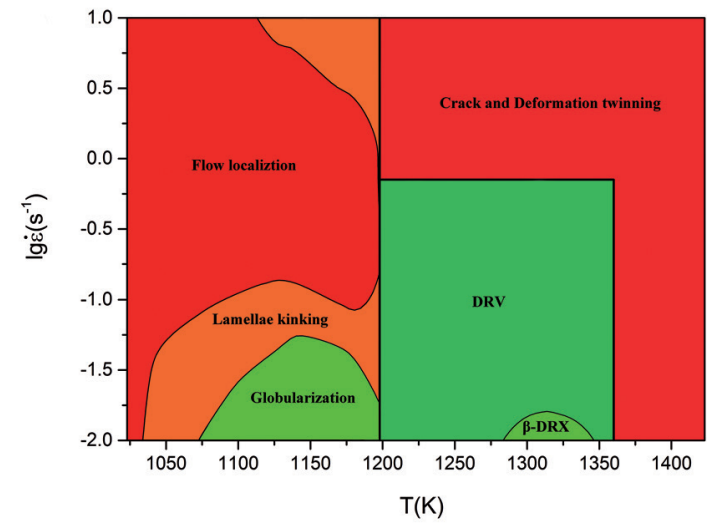

Figure 11: Microstructural deformation mechanism map for Ti6Al-4V-0.1Ru.

In $\beta$-phase field:

$$
\begin{aligned}
& Z=\dot{\varepsilon} \exp (331750 / R T) \\
& =4.49675 \times 10^{27} \times[\sinh (0.02252 \sigma)]^{5.1549}
\end{aligned}
$$

(3) According to DMM, the processing maps at the strain of $0.2,0.4,0.6,0.8$ were developed, the stable regions and instable regions were clarified clearly.
(4) The microstructural mechanisms during hot deformation were deeply understood by microstructure observation at different deformation conditions. Furthermore, a microstructural mechanism map was plotted based on processing maps and microstructures observation. As a result, deformation conditions in the vicinity of 1150 $\mathrm{K} \& 0.01 \mathrm{~s}^{-1}$ where globularization occurs and 1323 $\mathrm{K} \& 0.01 \mathrm{~s}^{-1}$ where $\beta$-DRX occurs are recommended.

\section{Acknowledgements}

This work was supported by National Natural Science Foundation of China (51305469).

\section{References}

1. Quan GZ, Lv WQ, Liang JT, Pu SA, Luo GC, Liu Q. Evaluation of the hot workability corresponding to complex deformation mechanism evolution for $\mathrm{Ti}-10 \mathrm{~V}-2 \mathrm{Fe}-3 \mathrm{Al}$ alloy in a wide condition range. Journal of Materials Processing Technology. 2015;221:66-79.

2. Zhang DY, Li HZ, Liang XP, Wei ZW, Liu Y. Microstructure characteristic for high temperature deformation of powder metallurgy $\mathrm{Ti}-47 \mathrm{Al}-2 \mathrm{Cr}-0.2 \mathrm{Mo}$ alloy. Materials \& Design. 2014;59:415-420. 
3. Shu XY, Lu SQ, Wang KL, Li GF. Optimization of hot working parameters of as-forged Nitinol 60 shape memory alloy using processing maps. Metals and Materials International. 2015;21(4):726-733.

4. Quan GZ, Wang Y, Yu CT, Zhou J. Hot workability characteristics of as-cast titanium alloy Ti-6Al-2Zr-1Mo-1V: A study using processing map. Materials Science and Engineering: A. 2013;564:46-56.

5. Srinivasan N, Prasad YVRK, Rama Rao P. Hot deformation behaviour of $\mathrm{Mg}-3 \mathrm{Al}$ alloy-A study using processing map. Materials Science and Engineering: A. 2008;476(1-2):146-156.

6. Wang S, Hou LG, Luo JR, Zhang JS, Zhuang LZ. Characterization of hot workability in AA 7050 aluminum alloy using activation energy and 3-D processing map. Journal of Materials Processing Technology. 2015;225:110-121.

7. Quan GZ, Zhao L, Chen T, Wang Y, Mao YP, Lv WQ, et al. Identification for the optimal working parameters of as-extruded 42CrMo high-strength steel from a large range of strain, strain rate and temperature. Materials Science and Engineering: $A$. 2012;538:364-373.

8. Prasad YVRK, Gegel HL, Doraivelu SM, Malas JC, Morgan JT, Lark KA, et al. Modeling of dynamic material behaviour in Hot Deformation: Forging of Ti-6242. Metallurgical and Materials Transactions A. 1984;15(10):1883-1892.

9. Murty SVSN, Rao BN, Kashyap BP. Instability criteria for hot deformation of materials. International Materials Reviews. 2000;45(1):15-26.

10. Jenab A, Taheri AK. Experimental investigation of the hot deformation behaviour of AA7075: Development and comparison of flow localization parameter and dynamic material model processing maps. International Journal of Mechanical Sciences. 2014;78:97-105

11. Saxena KK, Sonkar S, Pancholi V, Chaudhari GP, Srivastava D, Dey GK, et al. Hot deformation behaviour of $\mathrm{Zr}-2.5 \mathrm{Nb}$ alloy: A comparative study using different materials models. Journal of Alloys and Compounds. 2016;662:94-101.

12. Quan GZ, Kang BS, Ku TW, Song WJ. Identification for the optimal working parameters of $\mathrm{Al}-\mathrm{Zn}-\mathrm{Mg}-\mathrm{Cu}$ alloy with the processing maps based on DMM. The International Journal of Advanced Manufacturing Technology. 2011;56(9):1069-1078.

13. Prasad YVRK, Rao KP. Processing maps and rate controlling mechanisms of hot deformation of electrolytic tough pitch copper in the temperature range $300-950^{\circ} \mathrm{C}$. Materials Science and Engineering: A. 2005;391(1-2):141-150.

14. Anbuselvan S, Ramanathan S. Hot deformation and processing maps of extruded ZE41A magnesium alloy. Materials \& Design. 2010;31(5):2319-2323.
15. Lin YC, Chen XM. A critical review of experimental results and constitutive descriptions for metals and alloys in hot working. Materials \& Design. 2011;32(4):1733-1759.

16. Zhou M, Lin YC, Deng J, Jiang YQ. Hot tensile deformation behaviours and constitutive model of an $\mathrm{Al}-\mathrm{Zn}-\mathrm{Mg}-\mathrm{Cu}$ alloy. Materials \& Design. 2014;59:141-150.

17. Zhang J, Di H, Wang X, Cao Y, Zhang J, Ma T. Constitutive analysis of the hot deformation behaviour of $\mathrm{Fe}-23 \mathrm{Mn}-2 \mathrm{Al}-0.2 \mathrm{C}$ twinning induced plasticity steel in consideration of strain. Materials \& Design. 2013;44:354-364.

18. Lin YC, Chen MS, Zhong J. Constitutive modeling for elevated temperature flow behaviour of $42 \mathrm{CrMo}$ steel. Computational Materials Science. 2008;42(3):470-477.

19. He A, Xie GL, Zhang HL, Wang XT. A modified Zerilli-Armstrong constitutive model to predict hot deformation behaviour of 20CrMo alloy steel. Materials \& Design. 2014;56:122-127.

20. Yang ZN, Zhang FC, Zheng CL, Zhang M, Lv B, Qu L. Study on hot deformation behaviour and processing maps of low carbon bainitic steel. Materials \& Design. 2015;66(Pt A):258-266.

21. He DG, Lin YC, Chen MS, Chen J, Wen DX, Chen XM. Effect of pre-treatment on hot deformation behavior and processing map of an aged nickel-based superalloy. Journal of Alloys and Compounds. 2015;649:1075-1084.

22. Zhu Y, Zeng W, Feng F, Sun Y, Han Y, Zhou Y. Characterization of hot deformation behavior of as-cast TC21 titanium alloy using processing map. Materials Science and Engineering: A. 2011;528(3):1757-1763

23. Pu EX, Zheng WJ, Xiang JZ, Song ZG, Li J. Hot deformation characteristic and processing map of superaustenitic stainless steel S32654. Materials Science and Engineering: A. 2014;598:174-182.

24. Seshacharyulu T, Medeiros SC, Frazier WG, Prasad YVRK. Hot working of commercial Ti-6Al- $4 \mathrm{~V}$ with an equiaxed $\alpha-\beta$ microstructure: materials modeling considerations. Materials Science and Engineering: A. 2000;284(1-2):184-194.

25. Luo J, Li L, Li MQ. The flow behavior and processing maps during the isothermal compression of Ti17 alloy. Materials Science and Engineering: A. 2014;606:165-174.

26. Processing Maps: A Status Report. Journal of Materials Engineering and Performance. 2013;22(10):2867-2874.

27. Prasad YVRK, Rao KP, Hort N, Kainer KU. Optimum parameters and rate-controlling mechanisms for hot working of extruded $\mathrm{Mg}-3 \mathrm{Sn}-1 \mathrm{Ca}$ alloy. Materials Science and Engineering: A. 2009;502(1-2):25-31.

28. Seshacharyulu T, Medeiros SC, Frazier WG, Prasad YVRK. Microstructural mechanisms during hot working of commercial grade Ti-6Al-4V with lamellar starting structure. Materials Science and Engineering: A. 2002;325(1-2):112-125. 